\title{
Forming student self-organization culture as a factor of improving the educational process quality in higher education
}

\author{
N.V. Dyorina ${ }^{1 *}$, L.I. Savva ${ }^{2}$, and E.I. Rabina ${ }^{3}$ \\ ${ }^{1}$ Nosov Magnitogorsk State Technical University, Magnitogorsk, Russia \\ ${ }^{2}$ Nosov Magnitogorsk State Technical University, Magnitogorsk, Russia \\ ${ }^{3}$ Nosov Magnitogorsk State Technical University, Magnitogorsk, Russia
}

\begin{abstract}
The authors analyze the stated problem in philosophical, historical, psychological and pedagogical aspects, clarify the conceptual apparatus of the research, determine the structural components of the personality of a technical university student with self-organization culture, describe the developed structural and functional model of the formation of self-organization culture of a technical university student, implemented on the example of humanities disciplines, substantiate the set of pedagogical conditions of the considered process. The main goal of personal selforganization is to control one's life on the basis of optimal use of available opportunities and taking into account individual characteristics and abilities. It is determined that all this requires the individual to make efforts to restructure his or her life activities and involves self-reflection, selfmonitoring and self-correction of behavior.
\end{abstract}

\section{A problem statement}

The rapid development of the scientific and technical fields, the rapid pace of production development, the social and economic transformations taking place all over the world, and the transition to a digital society require not only the knowledge and skills required for professional activities, but also such socially important personal qualities as motivation for lifelong learning (long-life-learning) and the mastery of innovative technologies within the framework of professional activities. Modern production plants and companies of all kinds need a workforce composed of self-organized, qualified employees. In this regard, in the eco-educational environment of a technical university there is an increasing need to manage the process of developing students' self-organization skills.

In order to solve the problem of formation of self-organization abilities of an individual, education is understood as the most important option of culture, as "a mechanism of launching new forms of culture" [1], "expanded reproduction and translation of culture" [1]. One of the tasks of higher education is to ensure full-fledged development of a future specialist's personality, including the development of the ability to self-manage and self-

*Corresponding author: prof-ped.gpa@mail.ru 
regulate, to choose "a culturally appropriate way of life and behavior" [2]. The selforganization culture formed during higher education is the key to successful professional culture development, creative self-development and self-realization, achieving the peak of personal development.

The relevance of the research at the scientific-theoretical level is caused by insufficient theoretical development of the issues of formation of self-organization culture of a university student's personality.

The analysis of scientific and theoretical base shows that pedagogy has accumulated a certain amount of knowledge to solve the problem of formation of students' selforganization culture in the process of learning in higher education.

The concepts of "self-organization of personality" [3, 4], "self-organization of student's personality" [3, 5], "culture of self-organization" [6, 5], and "culture of self-organization" $[6,8]$ have been analyzed from different approaches, "culture of self-organization of educational and cognitive activity" [6, 8], "culture of personal self-organization" [9]; studied psychological bases of formation of personal self-organization $[10,3]$, the relationship between self-organization and the success of students' learning activities [11], the relationship between culture and self-organization [12]. A number of researchers [9] have considered means and methods of students' self-organization culture formation.

At the same time not all means and methods have been equally studied. So, pedagogical means and methods of formation of such culture remain insufficiently studied. The history of pedagogy and education has centuries of experience in using different types of art in the process of education, training and formation of personality. To date, in the works of domestic educators and psychologists [10, 13-17] many issues of training, education and development of students through art are comprehended. There are works highlighting individual aspects of the problem of using art-pedagogical means and methods. B.G. Ananiev highlights individual work as the most important condition for students' selforganization in mastering methods of professional education. B.G. Ananiev singles out the principles of students' individual work and compiles them into universal groups, which are the main conditions for effective formation of self-organization culture:

- Organizational principle includes time budgeting, application of teaching literature, use of academic and laboratory facilities in the eco-educational environment of a technical university;

- Methodological principle implies planning, teaching methods applied and monitoring the individual work of technical university students;

- Psychological and pedagogical principle includes consideration of psychological characteristics necessary for fast individual work with literature on specialty and development of social qualities of personality necessary for such work.

Among many problems arising in the formation of students' self-organization culture in technical university it is necessary to investigate such problems, which are related to specifying the content of the concepts "students' self-organization culture", "teaching tools", "teaching methods"; with identifying approaches to students' self-organization culture formation; with developing the model of students' self-organization culture formation in technical university; with substantiation of the process content of students' self-organization culture formation in technical university.

There are contradictions between the practical necessity of students' self-organization culture formation and insufficient development of content aspects of the process of its formation in pedagogical science; between the aspiration of university teacher to form students' self-organization culture and insufficient understanding of the fact that such formation can be realized by pedagogical means and methods.

Despite the wide coverage of the issues related to students' self-organization culture in technical university, theoretical foundations of the phenomenon of students' self- 
organization culture formation in scientific and pedagogical aspects are only beginning to be studied, some of them (key concepts, structure of students' self-organization culture in technical university, pedagogical conditions) are of debatable nature.

Improving the quality of the educational process in higher education institution depends on various factors, however, given the current living conditions of young people, the formation of student's self-organization culture in technical higher education institution is one of the most important, as it is aimed at creating conditions for the maximum use of personal abilities, conscious management of the flow of their life and successful overcoming of emerging obstacles.

The theoretical analysis of the stated problem showed that under the influence of socioeconomic and socio-cultural factors the theoretical and practical prerequisites for the formation of the process under study were formed.

The consideration of the category of "culture" in science has allowed us to realize that it is leading in the natural science picture of the world. The history of research into the phenomenon of culture demonstrates a variety of approaches to its interpretation and description.

The content of the concept "student's self-organization culture" has been revealed on the basis of such notions as "self-organization of personality", "self-organization of student's personality", "culture".

\subsection{The objective of the work}

The purpose of the study is to develop a model of student's self-organization culture in the eco-educational environment of a technical university.

In order to achieve this goal, it is necessary to analyze the problem of formation of student's self-organization culture in technical university in the historical context and at the present stage, which will allow to see possible variants of its solution; to specify concepts "self-organization culture" and "eco-educational environment of technical university", which expands the conceptual field of the problem under study.

Define the structure of students' self-organization culture in a technical university; determine the peculiarities of systemic, personal, activity and cultural approaches to formation of students' self-organization culture in a technical university, which streamlines and extends the methodological aspects of the problem and contributes to comprehension of the strategy of the process under study.

\section{Results of the research}

The concept of "self-organisation" is of particular interest to scholars in many fields of knowledge. An analysis of various definitions has made it possible to interpret selforganisation as a process of reproducing or improving the organisation of a complex dynamic system, aimed at establishing order in it. In this context, the human personality can be considered as a complex system, the level of self-management of which is determined by the development of its abilities for self-knowledge, self-organization, self-control, selfassessment, self-improvement, and others.

In the process of theoretical analysis of the studied phenomenon it was revealed that the ability to self-organization, along with a high level of motivation, cognitive and creative activity, is an indicator of personal maturity. The main goal of self-organization of a personality is to control his/her life on the basis of optimal use of available opportunities and taking into account individual characteristics and abilities. It has been determined that 
all this requires from the individual efforts aimed at restructuring of life activity, and involves self-analysis, self-control and self-correction of behaviour.

The university entrance and learning process require from the student at the present time great independence and organization on the background of increased information load, as well as adequacy in the changed conditions of education and social being. Under the given circumstances self-organization culture as a well-ordered conscious activity of a personality aimed at goal-setting, planning, rational time management, as well as self-control, selfanalysis and self-correction of actions and behaviour provides students with timely, rhythmical and consistent change of life cycles; it is the guarantee of productive and optimal life activity and, consequently, increases competitive ability and ensures successful professional training of university graduates.

The category of "culture" is interpreted by philosophers, pedagogues and psychologists. In domestic and foreign science culture is understood as a qualitative characteristic of an individual, the degree of development of her essential forces [18, 19], the "measure of power" of a person over his/her own physical and mental nature [6,11], the qualitative side of human activity $[20,2]$, the totality of material and spiritual values, the main factor of personal and professional development [21, 22], formation of professionalism [23], mechanism of self-perfection and self-realization of social space subjects [24]. In the works of researchers S.V. Elkin, I.F. Isaev, etc. [1] self-organization of a personality is considered from the point of view of the cultural approach as a set of cultural components, the most important of which are values and meanings (value of self-organization, personal meaning of mastering the culture of self-organization).

The analysis of the nature of notions "self-organization of personality", "selforganization of student's personality", "culture" allowed us to reveal their systemic role in interpretation of student's self-organization culture, which, in our opinion, should be understood as personal formation manifested in student's abilities to self-management, to rational organization of educational and cognitive activity and in awareness of these abilities as personal value. In determining the structure of students' self-organization culture, we proceeded from the content of the concept "students' self-organization culture", from the ideas of domestic and foreign researchers about the relationship between selforganization and learning activity motivation $[19,9]$, students' self-organization and values [25], motives and values, from ideas about the structure of self-organization of learning and cognitive activity, about the culture of learning work [25, 26], about knowledge as an essential element of culture [11], as well as from activity theories [13, 27].

The paper determines that the structure of cultural and self-organized personality of a technical university student (Table 1) is represented by the following interrelated blocks: motivational-value, cognitive and action-reflexive

Table 1. Structure of the personality of a technical university student with a culture of selforganisation.

\begin{tabular}{|c|c|c|c|}
\hline \multicolumn{4}{|c|}{ Motivation and value block } \\
\hline $\begin{array}{c}\text { Awareness of self- } \\
\text { organisation } \\
\text { as a value }\end{array}$ & $\begin{array}{l}\text { Awar } \\
\text { self-or }\end{array}$ & $\begin{array}{l}\text { f a culture of } \\
\text { tion as a value }\end{array}$ & $\begin{array}{c}\text { Motivation to develop a culture of self- } \\
\text { organisation }\end{array}$ \\
\hline \multicolumn{4}{|c|}{ Cognitive block } \\
\hline \multicolumn{4}{|c|}{ Knowing your personality traits } \\
\hline \multicolumn{2}{|c|}{$\begin{array}{l}\text { Knowledge of the culture of self- } \\
\text { organisation }\end{array}$} & \multicolumn{2}{|c|}{$\begin{array}{c}\text { Knowledge of ways of a culture of } \\
\text { self-organisation }\end{array}$} \\
\hline \multicolumn{4}{|c|}{ Action-reflection unit } \\
\hline \multicolumn{2}{|c|}{ Competences in goal-setting } & \multicolumn{2}{|c|}{ Competences in the area of culture of self-organisation } \\
\hline \multicolumn{2}{|c|}{ Planning competencies } & \multicolumn{2}{|c|}{ Reflexive skills in the area of a culture of self-organisation } \\
\hline
\end{tabular}


The study emphasizes the idea that the formation of self-organization culture of a technical university student is a specially organized process of interrelated activities of a teacher and students, aimed at creating pedagogical conditions to provide students with pedagogical assistance, support and assistance in developing their experience of selforganized behavior culture through the formation of value attitudes, sustainable motives, knowledge and competencies in the field under consideration.

The systemic representation needs the considered process and its purposeful management required modeling of student's self-organization culture formation in a technical university. The main requirements of systemic, personal, activity and culture approaches were chosen as a methodological basis for model development and implementation, the totality of which allows to comprehensively considering the logic and internal dynamics of the process under study.

Application of the systemic approach makes it possible to treat the developed model as a pedagogical system, defining its components, content and relations between them. The personal approach serves as a methodological basis for the implementation of pedagogical conditions of formation of self-organization culture of a technical university student and the methodology allowing a future specialist to become a multidimensional social personality and professional on the basis of self-organization culture.

The essence of the culture approach to formation of students' self-organization culture, in our opinion, consists in actualization of student's position as a subject of educational process; in such selection of content and means of educational process organization, when students master knowledge about personal self-organization culture, realize personal sense of mastering it, develop value attitude to personal self-organization culture, to personal and professional self-development and self-improvement.

The structural and functional model of students' self-organization culture in technical university, which is implemented on the example of humanities disciplines, includes the following components: purposeful, content-organizational, and methodical and resultevaluation. The indicated components are specified in relation to pedagogical system and its peculiarities. The choice of this type of model is explained by the fact that its structural components allow revealing the internal organization of the process under study, and the functional components represent stable basic links of structural components, conditioning its functioning.

The aim of the model was defined as the effective formation of the student's selforganization culture in a technical university. The stated goal is a short-term one, while the long-term goal is the effective formation of student's self-organization culture in the process of all life activities.

The subjective component of the model is represented by teachers and students. The minimum level of requirements to the subjects is determined by teachers' and students' readiness to implement the set of pedagogical conditions and the functions identified in the model, and the maximum level of requirements to the subjects - students' readiness to form the culture of self-organization.

Based on the conclusions obtained in the course of theoretical research and practical pedagogical activity, the content-organizational component of the model was developed, including the functions, the implementation of which provides the predictable result, the structure of the personality of a technical university student with self-organization culture and the set of pedagogical conditions of the considered process.

The paper substantiates that each of the functions corresponds to certain pedagogical conditions of formation of self-organization culture of a technical university student, which were singled out: 1) formation of student's value attitude to culture in eco-educational environment; 2) development of student's motivation to form self-organization culture by active application of pedagogical means and methods in classes; 3) development of 
student's experience of cultural self-organized behavior with the support of disclosure of his subjectivity.

The choice of the first condition was dictated by the fact that it is guided by value orientations that a person builds his/her behavior line. By focusing the subject's attention on himself and reflecting upon his activities, reflexing serves as a general mechanism for the self-regulation of a personality and lays the basis for the formation of an attitude of value within him.

The second condition is determined by the fact that the student enters a new ecoeducational environment to which he/she has to adapt by rationally planning, organizing and controlling the academic day and time outside the university. In such circumstances, the student's motivation to develop a culture of self-organization, in the development of which methods of critical thinking, i.e. thinking based on the use of cognitive skills and strategies that increase the probability of obtaining the desired result, becomes particularly important.

The necessity of introducing the third condition is connected with the fact that the orientation of behavioral choice is always a certain behavioral model as a certain image of personal interaction with the environment, and purposeful formation of the required behavior is possible only with a reliance on subjective experience.

\section{Conclusions}

The paper summarizes the main results of the study and outlines the following conclusions:

The paper specifies the following basic concepts of the study: 1) self-organization culture is an ordered conscious activity of a personality aimed at goal setting, planning, rational organization of time, as well as self-control, self-analysis and self-correction of actions and behavior during learning activities and beyond; 2) personality of a technical university student with self-organization culture is personal formation, manifested in student abilities to self-management, to rational organization of learning and cognitive activity of a student; 2) student's self-organization culture is a personality formation, manifested in the ability of a student to self-organize, to rationally organize learning and cognitive activity of a student. The student's self-organization culture includes four interrelated and interdependent components: cognitive, reflective, motivational-valuable and activity-oriented, each fulfilling its own functions.

The structure of a culturally self-organized personality of a technical university student is defined; the identified components (motivational-valuable, cognitive and action-reflexive blocks) and connections in this structure deepen the available scientific knowledge in pedagogical science.

The study specifies that the formation of a culturally self-organized personality of a technical university student is a specially organized process of interrelated activities of a teacher and students, aimed at creating pedagogical conditions for providing students with pedagogical assistance, support and assistance in developing their experience of behavior based on the culture of self-organization by introducing it to independent formulation and reflection of learning goals in higher education.

The structural and functional model of students' self-organization culture at a technical university is developed and theoretically proved. The model is realized by the example of humanities disciplines and includes target, content and organizational, methodical and result-evaluation components. It is determined that it reflects the logic and internal dynamics of the process under study due to the implementation of motivational, diagnostic, developing, organizational and reflexive functions. At the same time the possibilities of forming the culture of self-organization of a technical university student from the positions of systemic, personal, activity and culture approaches are disclosed. 
The methodological support of the investigated process including the methodology of pedagogical conditions realization, the program of special course "Students' selforganization culture in technical university", criteria-diagnostic tools, methodical recommendations for students and teachers "Development of self-organization culture skills of technical university students" was developed and tested on the example of humanities disciplines.

However, the conducted research does not exhaust all the aspects of the complex and multifaceted problem. The following directions seem promising from the point of view of further development of the problem: experimental work on the formation of students' selforganization culture in a technical university in the conditions of ecological educational environment, analysis of the cultural environment of a university as a factor of students' self-organization culture, development of an electronic educational-methodical complex as a means of forming students' self-organization culture in a technical university, development of theoretical-methodological and methodological aspects of the succession principle of school and university continuity in the formation of student's personality with the culture of self-organization.

\section{References}

1. I.F. Isaev, Professional and pedagogical culture of a teacher: textbook for students of higher education institutions, 208 (2002)

2. V.V. Silvestrov, Culture. Activity. Communication: a collection of articles, 478 (1998)

3. N.M. Peisakhov, M.N. Shevtsov, Practical Psychology (Scientific Fundamentals), 121 (1991)

4. G.P. Shchedrovitsky, Selected Works, 800 (1995)

5. M.N. Shevtsov, About a Possibility of Using Chronometric Methods for SelfGovernance Ability Estimation, Scientific Notes of Kazan University, 3(150), 129-138 (2008)

6. N.M. Talanchuk, The system-synergetic conception of pedagogy and educational process, 92 (1993)

7. N.Ya. Saygushev, I.A. Shcherbakova, Determination of the individual trajectory of professional development of students as a condition for increasing the effectiveness of their professional training, Humanitarian and pedagogical research, 4(1), 12-19 (2020)

8. G.P. Shchedrovitsky, Organizational-activity game as a method of complex sociopsychological research, Program-target approach and business games, $36-39$ (1980)

9. L.V. Faleeva, Organization and self-organization as a personality quality: a comparative analysis of the concepts, Modern problems of science and education, $\mathbf{4}$, 266-274 (2012)

10. L.S. Vygotsky, Psychology of Art, 344 (1987)

11. V.P. Bespalko, Programmed learning: didactic fundamentals, 300 (1970)

12. N.V. Gerasimova, R.R. Titiberia, Competitive environment as a factor in the formation of the innovative ecosystem of the university, Postulate, 6, 43-49 (2018)

13. B.G. Ananyev, Tasks of Psychology of Art, Artistic Creativity: a collection of articles, 236-242 (1982)

14. S.I. Arkhangelskiy, Lectures on the theory of training in higher school: to study the discipline, 384 (1974) 
15. N.B. Berkhin, General Problems of Psychology of Art, 64 (1981)

16. S.H. Rappoport, Art and Emotions, 160 (1968)

17. B.M. Teplov, Notes of psychologist in reading fiction, 328 (1985)

18. I.F. Isaev, Professional and pedagogical culture of a teacher: textbook for students of higher education institutions, 208 (2002)

19. L.N. Kogan, Spiritual Production and Culture, Issues of Spiritual Culture of Soviet Workers, 1, 3-15 (1969)

20. E.S. Markarian, Principles of Self-Organization and Integrative Interaction of Social, Natural and Technical Sciences, Methodological Problems of Science Interaction: Proceedings of IIET AS USSR, 225-240 (1981)

21. G.A. Vinogradova, T.P. Sashilova, Psychological resources of first-year students as a basis of professional formation, Bulletin of Samara Humanitarian Academy. Series: Psychology, 2, 74-86 (2009)

22. V.P. Zinchenko, Consciousness and the creative act, 592 (2010)

23. B.S. Gershunsky, Philosophy of Education for the XXI Century, 697 (1997)

24. E.I. Artamonova, Philosophical and pedagogical foundations for the development of the spiritual culture of the teacher, 450 (2000)

25. S.N. Kostromina, Structural and functional model of self-organization of activity, Bulletin of Saint-Petersburg University, 4, 153-160 (2010)

26. V.N. Kosyrev, Culture of Student's Learning Work, 154 (1997)

27. M.S. Kagan, Introduction to the History of World Culture, 320 (2003) 